\title{
Alicia C. Montoya, Marie-Anne Barbier et la tragédie post-classique
}

\section{Franco Piva}

\section{(2) OpenEdition}

10 Journals

\section{Édition électronique}

URL : http://journals.openedition.org/studifrancesi/8916

DOI : 10.4000/studifrancesi.8916

ISSN : 2421-5856

Éditeur

Rosenberg \& Sellier

\section{Édition imprimée}

Date de publication : 1 octobre 2008

Pagination : 455-456

ISSN : 0039-2944

\section{Référence électronique}

Franco Piva, «Alicia C. Montoya, Marie-Anne Barbier et la tragédie post-classique », Studi Francesi [En ligne], 155 (LII | II) | 2008, mis en ligne le 30 novembre 2015, consulté le 11 janvier 2021. URL : http:// journals.openedition.org/studifrancesi/8916; DOI : https://doi.org/10.4000/studifrancesi.8916

Ce document a été généré automatiquement le 11 janvier 2021.

\section{(c) (i) (9)}

Studi Francesi è distribuita con Licenza Creative Commons Attribuzione - Non commerciale - Non opere derivate 4.0 Internazionale. 


\title{
Alicia C. Montoya, Marie-Anne Barbier et la tragédie post-classique
}

\author{
Franco Piva
}

\section{RÉFÉRENCE}

ALICIA C. MONTOYA, Marie-Anne Barbier et la tragédie post-classique, Paris, Honoré Champion («Les Dix-huitièmes siècles», 106), 2007, pp. 594.

1 Parmi les nombreux auteurs, définis normalement mineurs, qui ont peuplé le panorama littéraire français de la fin du dix-septième et du début du dix-huitième siècle, c'est à dire pendant la longue fin du règne de Louis XIV, Marie-Anne Barbier constitue par bien des aspects un cas des plus significatifs et importants. Première dramaturge professionnelle de France, comme elle a été définie, Marie-Anne Barbier est l'auteur d'une œuvre riche et diverse. Ses tragédies, créées à la Comédie-Française, lui ont valu un succès d'estime et établi son nom d'auteur. Son œuvre lyrique et narrative a pris place - une place souvent originale - dans les débats qui ont marqué la Régence, notamment la Querelle des Anciens et des Modernes. Ses écrits poétiques et critiques lui ont permis de jouer un rôle non négligeable dans les réseaux littéraires de son époque. Le parcours par lequel cette femme a essayé de se créer une identité en tant qu'auteur est tel qu'il jette une lumière nouvelle sur la condition d'écrivain à cette époque charnière, qui marque le passage entre le siècle de Louis XIV et le siècle des Lumières. Son nom a pourtant disparu vite de la mémoire de ceux qui sont venus après elle, victime, comme bien d'autres, des simplifications que l'histoire littéraire, écrite le plus souvent au masculin, est amenée parfois à opérer, faussant ainsi la compréhension de ce qui s'est vraiment passé dans l'histoire littéraire, et plus largement culturelle, d'un pays.

2 Il fallait avant tout tenter de donner une identité à cette femme dont il nous est resté très peu de traces, et dont nous ne savions presque rien. C'est ce que Alicia C. Montoya a essayé de faire dans la première partie de son beau travail. Certes, les zones d'ombre 
sont encore nombreuses, mais les documents qu'elle a rassemblés, lui ont permis de situer Marie-Anne Barbier dans le contexte social et culturel dans lequel elle est née et dans lequel elle a vécu avant qu'elle ne parte à Paris pour tenter de devenir auteur, et qui a fortement marqué sa condition d'écrivain, ce qui plus est sa condition de femme écrivain. Car être une femme écrivain pour quelqu'un qui, comme Marie-Anne Barbier, sortait de la petite bourgeoisie de province, comportait une difficulté supplémentaire, et non des moindres: se donner une justification qui ne vienne ni du haut rang social, auquel elle n'appartenait pas, ni du fait d'appartenir à cette partie du genre humain à laquelle le travail littéraire était traditionnellement réservé. Tâche d'autant plus difficile si, comme le fit Marie-Anne Barbier, on cherchait à s'imposer dans ce genre "masculin" par excellence qu'était, à l'époque encore, la tragédie, parfaitement codifiée par les deux figures majeures de Corneille et de Racine qu'aucun auteur ne pouvait se permettre d'ignorer, encore moins un auteur femme.

Dans la deuxième partie de son travail, Alicia $\mathrm{C}$. Montoya a fait par conséquent voir comment Marie-Anne Barbier a réussi, ou du moins a tenté de construire son identité d'auteur dans un contexte aussi difficile. Dans ses tragédies - nous fait remarquer A. Montoya - elle a non seulement entretenu avec ses prédécesseurs, Corneille et Racine surtout, et à l'instar de la plupart de ses collègues, un dialogue continu, au moyen d'un jeu intertextuel très complexe qui fait apparaître la spécificité de ses tragédies, aussi bien d'ailleurs que de la plupart des tragédies écrites à cette époque "post-classique»; elle a surtout marqué son originalité en choisissant des sujets lui permettant de porter sur scène des personnages capables de mieux intepréter sa volonté de souligner le rôle joué, dans l'histoire, par cette autre partie du monde à laquelle elle appartenait. Dans son choix de mettre en scène quelques femmes fortes issues de l'histoire ancienne, Marie-Anne Barbier a utilisé la parole cornélienne et racinienne pour traiter une thématique qui lui permette de démontrer «la gloire de [son] sexe». Son œuvre relève donc avant tout - fait encore remarquer A. C. Montoya - d'une problématique de l'autorité: des autorités reconnues, qu'elles soient anciennes (sources antiques) ou modernes (nouveaux classiques), mais surtout de l'autorité discursive de Marie-Anne Barbier elle-même, femme auteur en quête d'une voix, qui d'abord prend appui sur l'exemple de celles qui l'ont précédée (Mlle de Scudéry in primis), quitte à s'en démarquer aussitôt pour chercher une originalité et une autorité qui lui appartiennent et qui ne dérivent que de sa propre «venue à l'écriture».

4 La reconstruction d'Alicia C. Montoya, fondée sur une analyse extrêmement poussée des quatre tragédies de Marie-Anne Barbier qui nous sont parvenues, et sur des instruments méthodologiques très modernes et parfaitement assimilés, est tout à fait convaincante. Son travail sera donc fort utile non seulement pour la connaissance de cette femme auteur qui méritait d'être enfin tirée de l'oubli dans lequel elle était injustement tombée, mais aussi pour une meilleure compréhension de ce théâtre "postclassique», qu'elle a pratiqué, et sur lequel la critique a finalement commencé à porter son attention. 